\section{Idoso em situação de finitude - percepção da equipe de enfermagem}

\author{
Braga, C \\ Enfermeira doutoranda em ciências da saúde IAMSPE. E- \\ mail: cris.br@terra.com.br \\ Pereira, RN \\ Enfermeira Hospital São Cristovão \\ Koike, $\mathbf{M}$ \\ Doutora e orientadora permanente mestrado e doutorado \\ IAMSPE \\ Pitanga, F \\ Professora da Universidade Nove de Julho \\ Ramos, $\mathbf{S}$ \\ Professora da Universidade Brasil \\ Neman, $\mathbf{F}$ \\ Coordenadora do curso de Enfermagem da Universidade \\ Brasil \\ Palavras Chave: Idoso, Finitude, Percepção, Enfermagem.
}

Introdução - O processo de finitude na maturidade pode ocorrer de forma lenta, com muito sofrimento físico, mental, social, emocional e espiritual e esse vem a ser um dos temas mais valorizados pela gerontologia e uma fonte de grande preocupação por parte dos pesquisadores, principalmente quando as pessoas denominam esse evento como normal e decorrente do processo de envelhecimento. Considera-se indivíduos em situação de finitude, aquele que se encontra fora das possibilidades terapêuticas curativas o que traz uma falsa ideia que nada pode ser feito. Metodologia - Tratou-se de uma pesquisa de campo, exploratória descritiva com abordagem qualitativa, que buscou descrever os cuidados paliativos em idosos em finitude e compreender as percepções da equipe de enfermagem no setor de Clinica Médica em cuidados paliativos com idosos. O estudo foi realizado em um Hospital privado que presta serviço e assistência à população predominantemente idosa. Os sujeitos que fizeram parte deste estudo incluem auxiliares, técnicos de enfermagem e enfermeiros, em um total de 18 elementos e que prestam cuidados aos idosos internados, que aceitaram participar do estudo mediante a assinatura do Termo de Consentimento Livre e Esclarecido (TCLE) e foi avaliado pelo Comitê de Ética em Pesquisa da sob o $\mathrm{n}^{\circ}$ da CAAE: 332959914.5.0000.5494. Apresentação dos resultados - A transcrição foi realizada a partir da fala dos sujeitos utilizando as palavras de significância em relação à percepção da equipe em aos cuidados paliativos por meio de quadros e diagramas, e posteriormente discutida em comparação a literatura utilizando a análise de Laurence Bardin. Os sujeitos do estudo compreendem que os Cuidados Paliativos estão relacionados com cuidados integrais prestados ao paciente para o alívio do sofrimento, alívio da dor, medidas de conforto, cuidados não invasivos, tratamento humanizado. Relataram que em idosos em fase terminal os cuidados paliativos estão relacionados com ciclo natural da vida, terapêutica humanizada, medidas de conforto, atendimento diferenciado, tratamento humanizado, respeito à privacidade e cuidados integrais. Os sujeitos acreditam que a equipe é capaz de proporcionar ao idoso em finitude uma morte menos sofrida, porém, é importante ressaltar que é necessário saber que está envolvido, familiares, emocional, quais são suas capacidades, suas necessidades e limitações, portanto os cuidados paliativos envolvem ações com base no conhecimento e no respeito aos valores do paciente e de sua família. Conclusão - Através dos resultados desse estudo, foi possível descrever e compreender as ações e percepções da equipe de enfermagem em idosos em sua finitude, os profissionais de enfermagem que participaram deste estudo evidenciaram a valorização da humanização dos cuidados paliativos, o conforto do paciente, o alívio da dor, além da importância da família, durante todo o processo terapêutico e a concordância de que pacientes terminais necessitam de apoio psicológico e espiritual neste momento.

\section{REFERÊNCIAS}

[1] ÁllVARES, Liége M; LIMA Rosângela C; SILVA Ricardo A. Cad. Saúde Pública vol.26 no. 1 Rio de Janeiro Jan. 2010

[2] BRAGANÇA, Joana F; Enfermeiros de Cuidados Paliativos: Como despendem o seu tempo e qual a sua percepção em relação à qualidade dos seus cuidados; Lisboa, Setembro de 2011.

[3] BRASIL. Ministério da Saúde. Academia Nacional de Cuidados Paliativos: Critério de Qualidade para os Cuidados Paliativos no Brasil. Ed. Diagraphic Editora Ltda, Rio de Janeiro. 2006.

[4] COSTA, Jéssyka C. M; SILVA, Larissa C; SILVA, Cleane R; A Ética do enfermeiro no cuidado a pacientes idosos sem possibilidade terapêutica de cura, Estud. interdiscip. envelhec., Porto Alegre, 2012.

[5] MELLO, AGC. Cuidados paliativos: abordagem contínua e integral. In: SANTOS FC. Cuidados paliativos: discutindo a vida a morte e o morrer. $1^{a}$ ed. São Paulo: Atheneu, 2009. Cap.18, p. 257-266. 